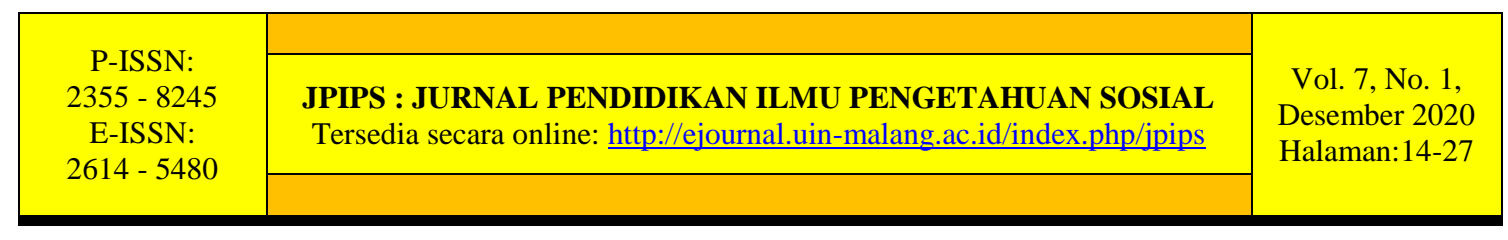

\title{
PENGEMBANGAN MODEL PEMBELAJARAN SAINTIFIK BERBASIS GOOGLE EARTH UNTUK MENINGKATKAN HASIL BELAJAR PEMETAAN GEOLOGI
}

\author{
Dwi Angga Oktavianto \\ SMK Negeri 1 Binuang \\ dwiangga.2018@student.uny.ac.id
}

Diterima: 21-09-2020.; Direvisi: 18-11-2020; Disetujui: 22-12-2020

Permalink/DOI: $10.1886 / j p i p s . v 7 i 1.10353$

\begin{abstract}
Abstrak: Penelitian ini dilakukan untuk menghasilkan suatu model pembelajaran bagi pembelajaran geologi ditingkat Sekolah Menengah Kejuruan. Model pembelajaran dihasilkan dengan memanfaatkan perkembangan teknologi geospasial, yakni Google Earth. Penelitian ini bertujuan untuk; (1) mengungkapkan hasil belajar siswa sebelum dan setelah penggunaan model pembelajaran berbasis Google Earth; (2) mengembangkan model pembelajaran saintifik berbasis Google Earth; dan (3) menguji efektifitas model yang dihasilkan. Penelitian ini merupakan penelitian Research and Development (R\&D) yang dilakukan di SMK Negeri 1 Binuang pada bulan September 2019. Subjek penelitian ialah 27 siswa kelas XII Geologi Pertambangan. Data penelitian didapat dari instrumen berupa angket, lembar observasi dan nilai hasil belajar siswa yang merupakan gabungan nilai unjuk kerja dan nilai proyek. Analisis data menggunakan; analisis isi pelajaran, analisis kelayakan produk pengembangan, dan analisis efektifitas dengan uji wilcoxson signed ranks. Hasil penelitian menunjukkan bahwa; (1) nilai hasil belajar siswa saat posttest lebih tinggi dibanding saat pretest; (2) Model pembelajaran saintifik berbasis Google Earth memiliki enam langkah pembelajaran; dan (3) Nilai signifikansi dengan uji wilcoxson signed ranks menunjukkan angka 0,000 yang jika dimaknai mengandung arti bahwa model pembelajaran saintifik berbasis Google Earth efektif digunakan. Model ini terbukti efektif pada pelajaran yang memiliki materi berupa data spasial (referensi keruangan).
\end{abstract}

\section{Kata Kunci: Model Pembelajara; Saintifik; Google Earth; Hasil Belajar}

Abstract: This research was conducted to produce a learning model for geology learning at the Vocational High School level. The learning model is generated by utilizing the development of geospatial technology, namely Google Earth. This research also aims to; (1) disclose student learning outcomes before and after using the Google Earth-based learning model; (2) developing a scientific learning model based on Google Earth; (3) testing the effectiveness of the resulting model. This research is a Research and Development $(R \& D)$ research conducted at SMK Negeri 1 Binuang in September 2019. The research subjects were 27 students of class XII Mining Geology. Research data obtained from instruments in the form of questionnaires, observation sheets and student learning outcomes which are a combination of performance scores and project values. Data analysis using; lesson content analysis, product development feasibility analysis, and effectiveness analysis using the Wilcoxson signed ranks test. The results showed that; (1) the value of student learning outcomes at posttest was higher than at pretest; 
(2) Google Earth-based scientific learning model has six learning steps; and (3) The significance value with the Wilcoxson signed ranks test shows the number 0.000 which, if interpreted, means that the Google Earth scientific-based learning model is effectively used. This model is proven effective in lessons that have material in the form of spatial data (spatial reference).

\section{Keywords: Learning Model; scientific; Google Earth; Learning Outcomes}

\section{PENDAHULUAN}

Permasalahan yang terjadi dalam pembelajaran pemetaan geologi sangat beragam. Pertama, siswa mengalami kesulitan untuk memvisualisasikan data struktur geologi tiga dimensi (3D) kedalam bentuk dua dimensi (2D) (Gagnier dkk. 2017). Siswa juga harus menerjemahkan model blok dan diagram berbentuk 2D yang biasanya guru gunakan di kelas ke fenomena geologi pada dunia nyata (Mathiesen dkk. 2012). Siswa yang memiliki kemampuan visualisasi yang kurang baik hanya menghafal dan menerapkan aturan, sehingga kurang mampu memvisualisasikan struktur geologi (Whitmeyer dkk. 2012). Hal ini ditambah terkendalanya guru mencari model pembelajaran yang cocok dengan karakteristik materi struktur geologi. Ini mengakibatkan belajar geologi menjadi sangat sulit karena tidak mudah memvisualkan strukturstruktur geologi.

Kedua, buku teks yang selama ini beredar belum mampu menampilkan tampilan visual yang dapat mempermudah siswa belajar geologi. Buku yang ada baru sebatas menampilkan berbagai macam materi geologi secara 2D (Farmer, Catalano, dan Halpern 2020). Guru perlu mengembangkan pendamping buku teks, agar siswa lebih mudah melakukan visualisasi, terutama dalam materi-materi yang menyangkut struktur geologi (Kortz, Grenga, dan Smay 2017). Pendamping buku teks juga diusahakan memiliki manfaat lain, yakni mampu menghadirkan berbagai macam bentukan struktur geologi (Trofimov dan Korolev 2019). Hal ini dilakukan karena tidak semua daerah memiliki struktur geologi yang lengkap, jadi terkadang sulit menemukan struktur geologi tertentu di sekitar sekolahan. Pembelajaran dengan hanya memanfaatkan buku teks sebagai bahan dalam model pembelajaran ceramah ternyata tidak mampu membuat siswa menjadi tertarik belajar geologi, sehingga membuat siswa sullit memahami.

Ketiga, siswa masih mengalami masalah dalam pengukuran terutama mengenai skala, jarak serta arah. Siswa masih kesulitan menghafal arah (orientasi), hal ini menimbulkan salah persepsi ketika mereka membuat sketsa dengan bantuan busur untuk penentuan arah (Trofimov dan Korolev 2019). Masalah skala peta muncul karena ketidakmampuan siswa dalam merubah satuan dari meter ke sentimeter dan sebaliknya. Ini merupakan kelemahan mendasar dalam belajar mata pelajaran yang berkaitan dengan pemetaan (Balliet, Riggs, dan Maltese 2015). Model pembelajaran berbasis proyek yang pernah guru gunakan dalam pembelajaran memiliki banyak kendala karena kelemahan tersebut (Oktavianto 2017). Padahal guru juga sudah menyediakan Global Positioning System (GPS), kompas, busur, dan meteran sebagai alat praktik. Ini memberikan gambaran bahwa ketersedian alat oraktik pembelajaran belum tentu mampu menjadikan siswa terampil dalam kompetensi-kompetensi dasar seperti menentukan skala, jarak, dan arah.

Keempat, siswa dalam mata pelajaran Pemetaan Geologi belum mampu menentukan strike (jurus) dan dip (sudut) secara tepat. Hal ini berkaitan dengan masalah pertama, yakni ketidakmampuan siswa dalam melakukan gambaran visual struktur geologi ketika di lapangan (Lamotte dkk. 2020). Siswa perlu diberikan gambaran visual yang tidak hanya berupa gambar 2D, mereka perlu mempelajari visual 3D agar saat di lapangan tidak mengalami kebingungan dalam menentukan jurus dan sudut (Dolphin dkk. 2019). Model pembelajaran outdoor di sekitar 
kelas dengan memanfaatkan lereng-lereng di sekitar sekolah ternyata tidak cukup mampu memberikan gambaran kepada siswa mengenai pengukuran jurus dan sudut (Lamb dan Johnson 2010). Keterampilan memvisualkan merupakan hal penting dalam belejar geologi, namun banyak siswa yang belum mampu menggunakannya.

Masalah yang telah disampaikan di atas berpotensi untuk memunculkan masalah kelima (masalah utama) diakhir pembelajaran, yakni rendahnya nilai hasil belajar siswa (Mills dkk. 2020; Schiappa dan Smith 2019; Sit dan Brudzinski 2017). Dalam mata pelajaran pemetaan geologi seharusnya tidak boleh ada siswa yang hasil belajarnya rendah, karena Ujian Kompetensi Keahlian (UKK) saat akhir Kelas 13 (Tiga Belas) nanti salah satunya berupa pemetaan geologi. Namun, kelima masalah yang ada memunculkan kekhawatiran bagi guru bahwa ketidaksesuaian model pembelajaran yang digunakan dengan karaktersitik materi menimbulkan rendahnya hasil belajar siswa (Balliet dkk. 2015). Guru sudah berusaha menggunakan berbagai model pembelajaran, dari ceramah, outdoor, sampai model saintifik berupa pembelajaran berbasis proyek namun masalah tetap belum dapat teratasi (Oktavianto 2017, 2020). Ini juga ditunjukkan hasil observasi selama mengajar geologi bahwa sebagian besar siswa masih belum memenuhi Kriteria Ketuntasan Minimal (KKM) yang telah diteptapkan.

Berbagai permasalahan dan harapan yang telah disampaikan di atas, memberi tantangan terhadap guru agar memanfaatkan perkembangan teknologi, terutama teknologi geospasial dalam mengembangkan sebuah model pembelajaran. Google Earth merupakan salah satu teknologi geospasial yang dapat menampilkan topografi dari bumi. Kelebihan Google Earth antara lain; (1) resolusi tinggi dan gambarnya baik; (2) gratis dan setiap siswa dapat menggunakannya di komputernya sendiri; (3) area dengan kontras warna yang kuat di antara unit sudah terlihat seperti peta geologis; (4) Google Earth memiliki tampilan "tilt-and-fly" medan interaktif 3D, yang merupakan kunci untuk membantu siswa memvisualisasikan koneksi antara pola dan struktur geologi (Oktavianto 2020).

Permasalahan yang ada perlu dicarikan solusi. Peneliti mengembangkan model pembelajaran saintifik berbasis Google Earth sebagai salah satu solusi menyelesaikan permasalahan yang ada. Hal ini dilandasi bahwa peneliti pernah memanfaatkan Google Earth dalam pembelajaran dengan cara memadukannya melalui model pembelajaran yang telah ada (Oktavianto 2017, 2020). Terkadang muncul kendala karena model yang dipadukan dengan Google Earth mempunyai sintaks yang tidak sesuai dengan karakteristik Google Earth. Peneliti mempunyai keyakinan, bahwa Google Earth akan lebih maksimal jika digunakan dengan model pembelajaran tersendiri yang dikembangkan dengan pendekatan saintifik. Model pembelajaran berbasis Google Earth ini dikembangkan untuk membantu siswa agar dapat belajar secara menyenangkan (Awada dan Diab 2018), menumbuhkan kreativitas siswa (Nikolopoulou 2018), memanfaatkan perkembangan teknologi untuk peningkatan keterampilan berpikir spasial (Xiang dan Liu 2017), serta meningkatkan aktivitas siswa dalam belajar geologi (Paor dkk. 2017).

Google Earth mempunyai potensi yang unik untuk berkontribusi terhadap pembelajaran. Penelitian terdahulu mengenai pembelajaran dengan menggunakan Google Earth, menyebutkan bawha pembelajaran tersebut mempunyai potensi; (1) Visualiassi pada tampilan virtual berpotensial mendukung pengalaman belajar yang kompleks, terutama pada fenomena-fenomena yang tidak mungking dilakukan tanpa bantuan virtual. (2) Sifat yang mendalam dari dunia virtual mendukung eksplorasi secara mandiri. (3) Dunia virtual sangat menarik dan memotivasi. (4) Dunia virtual memberikan cara pandang baru dalam melakukan penilaian otentik, otomatis, dan tertanam secara baik (Kafai dan Dede 2014). Keempat potensi tersebut memberikan gambaran bahwa dampak belajar melalui Google Earth dapat memberi kemudahan dalam melihat fenomena-fenomena geologi, sehingga siswa lebih tertarik dan termotivasi untuk melakukan 
eksplorasi secara mandri. Guru juga dapat melakukan penilaian secara otentik, dan otomatis terhadap pemahaman siswa yang tertanam selama belajar menggunakan Google Earth.

Google Earth dapat diakses secara gratis, mudah digunakan, sehingga memudahkan dalam membedakan bentang lahan alamiah dan buatan, membantu belajar memvisualkan, dan memahami proses yang terjadi di permukaan bumi (Oktavianto 2017). Belajar memvisualkan sangat penting bagi siswa yang sedang belajar dasar-dasar geologi, karena mereka masih memerlukan aktivitas-aktivitas yang dapat mengembangkan kemampuan merubah tampilan 3D ke dalam tampilan 2D atau sebaliknya. Google Earth merupakan teknologi yang mampu menampilkan kenampakan geologis secara sederhana, salah satunya merubah tampilan 2D pada peta atau cross section kedalam tampilan 3D sehingga lebih mudah dipahami oleh siswa (De Donatis, Susini, dan Foi 2012).

Pembelajaran dengan memanfaatkan Google Earth perlu menggunakan pendekanan multidisplin ilmu agar tercapai tujuan belajar sesuai dengan kurikulum dan kemampuan individu siswa (Lamb dan Johnson 2010). Jadi Google Earth dapat menjembatani antara standar yang harus dicapai dalam pembelajaran serta kecepatan belajar masing-masing individu, sehingga Google Earth sangat memungkinkan menjadi sebagai dasar dalam pembelajaran saintifik. Hal ini sesuai dengan hasil penelitian (Almquist, Blank, dan Estrada 2012) bahwa pembelajaran dengan Google Earth mempunyai kelebihan karena membiasakan siswa menggunakan teknologi, belajar menganalisis, dan memahami konsep secara spesifik. Hal ini perlu didukung pengembangan sebuah model pembelajaran sehingga pemanfaatan teknologi geospasial ini dapat dilakukan secara utuh.

Pembelajaran dengan memanfaatkan Google Earth perlu dirancang dengan cermat dan tepat. Model pembelajaran yang dikembangkan berdasarkan pembelajaran saintifik (Direktorat Pembina SMA, 2014). Pembelajaran saintifik berisi lima langkah; 1) mengamati; 2) menanya; 3) mengumpulkan informasi; 4) mengasosiasikan; dan 5) mengkomunikasikan. Diharapkan siswa akan melakukan kelima langkah tersebut. Sementara itu Google Earth akan digunakan siswa pada setiap langkah pembelajaran. Pembelajaran saintifik berbasis Google Earth akan memberikan siswa pengalaman belajar yang sangat berguna dalam memahami materi yang mereka pelajari.

Pemetaan geologi memiliki beberapa tahapan. Tahapan pemetaan geologi adalah sebagai berikut; (1) penentuan lokasi yang akan dipetakan; (2) pengambilan data di lapangan; (3) pengolahan data; (4) plotting data; dan (5) mendesain layout peta (Sukandarrumidi, 2011). Dalam pembuatan peta geologi, siswa harus memiliki keterampilan spasial yang baik untuk membaca peta topografi (Oktavianto 2018). Google earth dapat meningkatkan keterampilan berpikir spasial siswa (Oktavianto 2017). Penggunaan Google Earth diyakini dapat menjadikan siswa mampu membaca peta topografi sebagai peta dasar dalam membuat peta geologi, sehingga juga memungkinkan dapat membantu siswa dalam membuat peta geologi.

Rumusan masalah yang penulis ajukan dalam mengatasi berbagai permasalahan yang ada dalam pembelajaran geologi adalah sebagai berikut; (1) Bagaimana kondisi pembelajaran geologi sebelum dan setelah penggunaan model pembelajaran saintifik berbasis Google Earth); (2) Bagaimana mengembangkan model pembelajaran saintifik berbasis Google Earth?; dan (3) Efektifkan model tersebut digunakan dalm pembelajaran pemetaan geologi?

\section{METODE}

Metode $\mathrm{R} \& \mathrm{D}$ digunakan pada penelitian ini karena penelitian ditujukan untuk mengasilkan sebuah model pembelajaran. Model pembelajaran yang aplikatif dan memanfaatkan perkembangan teknologi geospasial sangat dibutuhkan untuk mata pelajaran ilmu kebumian. 
Kebutuhan tersebut menjadikan peneliti yakin bahwa Metode R \& D dapat diandalkan untuk menghasilkan sebuah model pembelajaran berbasis teknologi geospasial berupa Google Earth yang efektif digunakan. Subjek penelitian R\&D ini ialah siswa kelas XII Geologi Pertambangan yang berjumlah 27 siswa. Penelitian dilakukan pada bulan September 2019

$\mathrm{R} \& \mathrm{D}$ ini dilaksanakan dengan menggunakan tiga tahap utama. Tiga tahap tersebut ialah penelitian pendahuluan, penelitian pengembangan, dan pengujian. Ketiga tahap tersebut diyakini mampu untuk menjawab rumusan masalah yang diajukan. Dari tahapan ini kemudian dilakukan analisis kebutuhan, analisis hasil perencanaan, analisis hasil pengembangan, dan terakhir analisis implementasi untuk menguji efektifitas model yang dikembangkan. Ketiga tahap tersebut dapat dilihat pada gambar berikut ini:

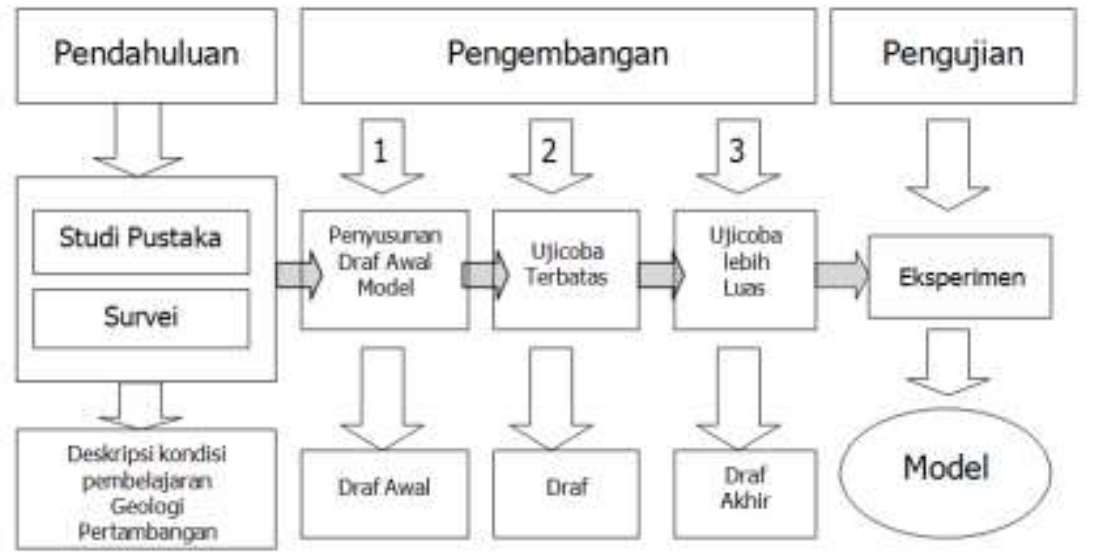

Gambar 1. Metode R \& D (Modifikasi Sukmadinata, 2005)

\section{HASIL DAN PEMBAHASAN \\ Hasil \\ Hasil Analisis Kebutuhan}

Analisis kebutuhan ini mengacu pada kondisi pembelajaran geologi pertambangan. Kondisi tersebut dapat terekam melalui studi pustaka dan survey berupa wawancara yang telah dilakukan terhadap siswa geologi pertambangan. Hasil akhir dari analisis kebutuhan dalam penelitian ini ialah sebuah model pembelajaran yang dapat diterapkan dalam pembelajaran geologi pertambangan.

Dalam dunia pendidikan dewasa ini muncul berbagai model pembelajaran. Model-model pembelajaran tersebut memiliki dasar teori masing-masing (Awada dan Diab 2018; Balliet dkk. 2015; Dolphin dkk. 2019; Gagnier dkk. 2017). Model Pembelajaran berbasis Teknologi Informasi Komunikasi (TIK) sekarang menjadi trend menarik untuk dikembangkan. Pembelajaran TIK yang sangat mungkin dikembangkan dalam pembelajaran geologi ialah pembelajaran TIK berbasis geospasial teknologi (Nikolopoulou 2018). Hasil wawancara yang dilakukan terhadap siswa geologi pertambangan mengenai pembelajaran yang menurut siswa menarik. Siswa tertarik dengan pembelajaran yang menggunakan perkembangan TIK. Hal ini wajar mengingat sebagian besar dari siswa merupakan "native technology" atau generasi yang lahir dalam masa perkembangan teknologi (Nikolopoulou 2018). Siswa juga menginginkan pembelajaran yang berupa fieldwork, karena selama ini pembelajaran hanya di ruang kelas dan lingkungan sekolah. Siswa merasa bahwa pembelajaran yang dilakukan selama ini tidak cukup untuk memberi mereka keterampilan geologi. 
Perpaduan antara penggunaan TIK dan fieldwork merupakan kebutuhan bagi pembelajaran geologi pertambangan. TIK yang digunakan berupa teknologi geospasial yang terintegrasi dalam pembelajaran (Nikolopoulou 2018). Sedangkan fieldwork merupakan karektristik pembelajaran yang berkaitan dengan alam (Balliet dkk. 2015). Dengan perpaduan TIK berbasis geospasial dan fieldwork menjadikan pembelajaran geologi pertambangan menarik siswa untuk belajar dan mendorong siswa untuk aktif dalam belajar (Almquist dkk. 2012; Bodzin, Anastasio, dan Kulo 2014; Martínez-Graña dkk. 2014). Teknologi geospasial yang dapat diandalkan untuk menghadirkan pembelajaran TIK dan fieldwork ialah virtual globe berupa Google Earth.

\section{Hasil Perencanaan}

Pembelajaran berbasis Google Earth menggunakan pembelajaran saintifik sebagai acuan. Pembelajaran saintifik berisi lima langkah; 1) mengamati; 2) menanya; 3) mengumpulkan informasi; 4) mengasosiasikan; dan 5) mengkomunikasikan. Dengan menerapkan langkah pembelajaran sanitifik diharapkan siswa akan melakukan langkah-langkah ilmiah selama proses pembelajaran, sehingga mereka terbiasa berpikir runut dan logis.

Tabel 1. Langkah Pembelajaran Berbasis Google Earth

\begin{tabular}{lll}
\hline No & \multicolumn{1}{c}{$\begin{array}{c}\text { Pembelajaran } \\
\text { Saintifik }\end{array}$} & \multicolumn{1}{c}{ Pembelajaran Berbasis Google Earth } \\
\hline 1. & Mengamati & $\begin{array}{l}\text { Mengidentifikasi citra Google Earth sesuai } \\
\text { dengan tujuan pembelajaran. } \\
\text { Merumuskan permasalahan yang bersumber dari } \\
\text { 2. }\end{array}$ Menanya \\
3. & Mengumpulkan & $\begin{array}{l}\text { Melakukan pemasukan data yang didapat dari } \\
\text { lapangan ke dalam Google Earth. }\end{array}$ \\
4. & Mengasosiasikan & $\begin{array}{l}\text { Memanfaatkan fitur-fitur Google Earth untuk } \\
\text { mengolah data lapangan agar dapat menjawab } \\
\text { rumusan masalah. } \\
\text { 5empresentasikan hasil jawaban dari rumusan } \\
\text { masalah menggunakan Google Earth. }\end{array}$ \\
\hline
\end{tabular}

\section{Hasil Pengembangan}

Hasil validasi berada pada nilai $85,23 \%$. Berdasarkan kriteria tingkat kevalidan yang telah ditetapkan oleh Suharsimi Arikunto (2013), maka nilai 85,23\% tersebut berada pada tingkat sangat valid. Tahap perancangan menjadi dasar peneliti untuk memperbaiki model pembelajaran berbasis Google Earth pada tahap pengembangan ini. Pada tahap pengembangan ini, model pembelajaran berbasis Google Earth yang telah dirancang diuji cobakan terhadap tujuh siswa geologi pertambangan kelas XII. Setiap siswa dikenalkan dengan model pembelajaran berbasis Google Earth. Siswa dibawa ke laboratorium komputer yang di dalamnya sudah terinstal komputer yang ada program Google Earthnya. Siswa mencoba belajar melalui model pembelajaran Google Earth.

Siswa setelah mencoba penggunaan model pembelajaran Google Earth diberikan kuisioner mengenai daya tarik model pembelajaran tersebut. Hasil dari kuisioner digunakan untuk penyempurnaan model. Hal ni perlu dilakukan karena model pembelajaran yang disusun 
perlu mendapat tanggapan dari siswa. Hasil kuisioner dapat dilihat pada Tabel 2. Kuisioner menggunakan; Tidak Menarik (TM); Kurang Menarik (KM); Menarik (M); dan Sangat Menarrik (SM). Jumlah siswa yang memilih tersebut kemudian dijumlahkan dan dibuat persentase dari keseluruhan siswa. Hasil dari pengembangan yang dimintakan tanggapan kepada siswa geologi pertambangan adalah seperti berikut ini;

Tabel 2. Tanggapan Awal Siswa terhadap Model Pembelajaran Berbasis Google Earth

\begin{tabular}{|c|c|c|c|c|c|}
\hline \multirow[b]{2}{*}{ No } & \multirow[b]{2}{*}{ Aspek Penilaian } & \multicolumn{3}{|c|}{ Tingkat Ketertarikan Siswa } & \multirow[b]{2}{*}{ SM \% } \\
\hline & & TM\% & KM \% & М \% & \\
\hline 1. & $\begin{array}{l}\text { Penentuan lokasi } \\
\text { yang akan dipetakan }\end{array}$ & & & 71,43 & 28,57 \\
\hline 2. & $\begin{array}{l}\text { Pengambilan data di } \\
\text { lapangan }\end{array}$ & & 57,14 & 42,86 & \\
\hline 3. & Pengolahan data & & 28,57 & 28,57 & 42,86 \\
\hline 4. & Plotting data & & & & 100 \\
\hline 5. & $\begin{array}{l}\text { Mendesain layout } \\
\text { peta }\end{array}$ & & & 28,57 & 72,43 \\
\hline Jun & & 0 & 17,14 & 34,28 & 48,57 \\
\hline
\end{tabular}

Tabel 2. di atas menunjukkan bawah secara umum siswa tertarik untuk belajar pemetaan geologi menggunakan model pembelajaran berbasis Google Earth. 48,57\% menyatakan bahwa secara umum model ini sangat menarik, $34,28 \%$ berpendapat menarik, dan hanya $17,14 \%$ yang mengatakan bahwa pembelajaran dengan berbasis Google Earth kurang menarik. Tidak ada siswa yang menyatakan tidak menarik.

Siswa menilai aspek-aspek dalam pemetaan geologi berbeda-beda tingkat menariknya jika dipelajari dengan Google Earth. Semua siswa sangat tertarik menggunakan Google Earth dalam aspek plotting. Sebagian besar siswa sangat tertarik membuat desain layout peta dengan bantuan Google Earth.

Aspek yang menurut siswa tidak cocok (kurang menarik) menggunakan Google Earth adalah pada saat pengambilan data. Pengambilan data yang berupa strike dan dip, serta sampel batuan menurut siswa tidak akan terbantu dengan adanya model pembelajaran Google Earth. Ada juga siswa yang beranggapan bahwa model pembelajaran ini tidak akan membantu dalam pengolahan data, sehingga mereka menilai Google Earth kurang menarik dalam hal pengolahan data lapangan.

\section{Hasil Implementasi}

Hasil implementasi merupakan uji penelitian berupa eksperimen semu pada kelas kontrol. Hal ini dilakukan karena jumlah kelas paralel Geologi Pertambangan hanya satu kelas. Subyek yang dijadikan penelitian adalah kelas XII GP dengan jumlah 27 siswa. Hasil uji t-test menunjukkan angka signifikasi sebesar 0,00. Angka ini lebih rendah dari nilai ambang batas signifikasi 0,05 sehingga dapat dinyatakan bahwa model pembelajaran berbasis Google Earth efektif digunakan dalam pembelajaran pemetaan geologi. Efektifitas penggunaan model pembelajaran Google Earth dalam pemetaan geologi juga didukung data nilai hasil belajar siswa. Nilai hasil berlajar diperoleh melalui pretest (sebelum penggunaan model pembelajaran berbasis Google Earth) dan posttest (sesudah penggunaan model pembelajaran berbasis Google Earth). Instrumen penilaian berupa non tes berbentuk penilaian proyek yang disusun dengan 
menggunakan indikator (aspek) pemetaan geologi menurut Sukandarrumidi (2011). Jumlah indikator terdiri dari lima butir, satu butir soal merupakan satu aspek dalam pemetaan geologi.

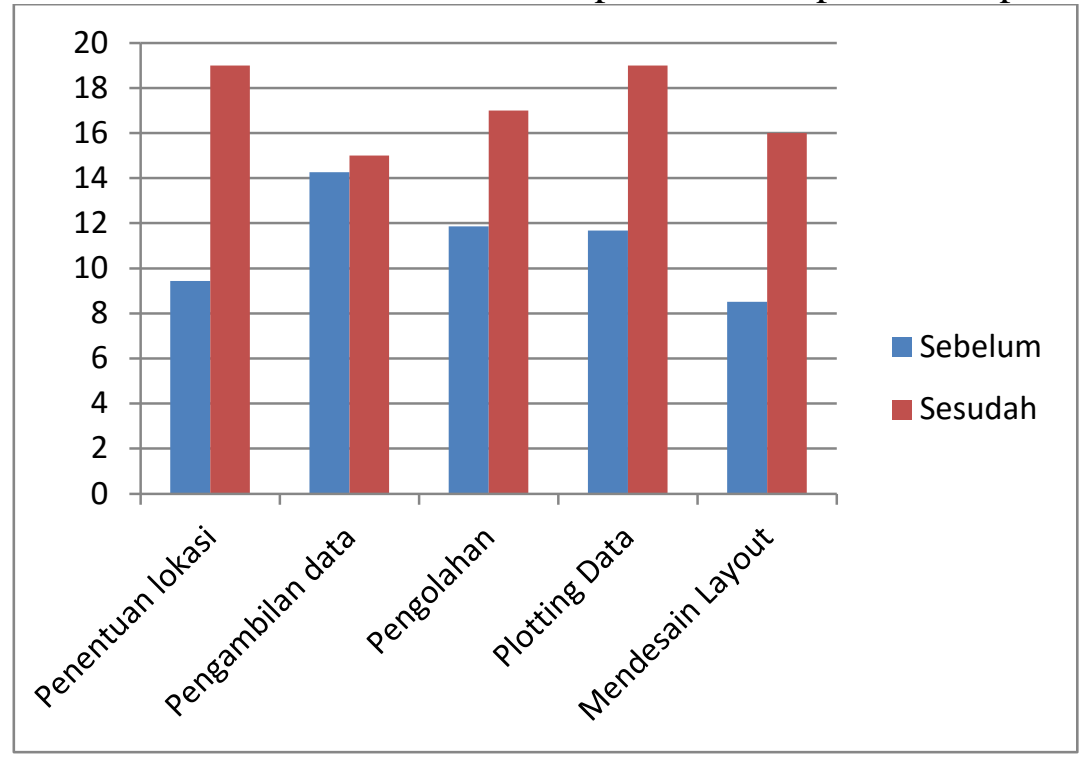

Gambar 2. Diagram Batang Hasil Belajar Siswa Sebelum dan Setelah Penggunaan Model Pembelajaran Google Earth

\section{Pembahasan}

Pembelajaran yang biasanya dilakukan kebanyakan guru geologi di Indonesia ialah "Pembelajaran Tanpa Nama". Jika guru menggunakan sebuah model pembelajaran bernama, biasanya tidak mengikuti sintak yang ada pada model pembelajaran tersebut. Hal ini menimbulkan kegagalan belajar. Istilah lain menyebutkan retensi siswa rendah. Hasil belajar siswa sebelum menggunakan model pembelajaran berbasis Google Earth (Gambar 2) membuktikan bahwa retensi siswa Geologi Pertambangan sangat rendah. Pembelajaran dengan hasil retensi yang rendah adalah sangat sulit diharapkan akan menjadi dasar tumbuhkembangnya pengetahuan, sikap dan keterampilan apalagi perilaku. Retensi yang rendah merupakan akibat dari berbagai permasalahan yang sesuai dengan penelitian terdahulu (Mills dkk. 2020; Schiappa dan Smith 2019; Sit dan Brudzinski 2017).

Retensi siswa dalam pengetahuan rendah tercermin dari hasil layout peta geologi yang mereka hasilkan. Layout yang seharusnya sesuai dengan Standar Nasional Indonesia (SNI) Pemetaan Geologi dengan kaidah-kaidah serta unsur-unsur yang sudah ditentukan saja siswa masih banyak yang tidak mengikuti aturan. Ini sesuai yang disampaikan oleh Gagnier, dkk. (2017). Siswa yang memiliki kemampuan visualisasi yang kurang baik hanya menghafal dan menerapkan aturan, sehingga kurang mampu memvisualisasikan struktur geologi. Hal ini dalam penelitian ditunjukkan dengan siswa membuat peta secara seenaknya tanpa memperhatikan SNI tersebut.

Keterampilan siswa masih rendah dalam mempraktikkan penggunaan peralatan-peralatan geologi lapangan. Rendahnya keterampilan siswa membuat data strike dan dip yang mereka dapat juga tidak benar. Data yang tidak benar akhirnya menghasilkan peta geologi yang salah. Hal ini terjadi karena kemampuan siswa dalam membaca peta dasar rendah, sehingga saat penentuan strike dan dip mereka salah orientasi (arah) (Lamotte dkk. 2020). Dalam melakukan deskripsi batuan siswa juga masih mengalami kesulitan, sehingga salah menamai batuan. Siswa perlu diberikan gambaran visual yang tidak hanya berupa gambar 2D, mereka perlu mempelajari visual 3D agar saat di lapangan tidak mengalami kebingungan dalam menentukan jurus dan 
sudut (Dolphin dkk. 2019). Retensi yang rendah pada pengetahuan, sikap, dan keterampilan membuat perilaku siswa di lapangan juga tidak baik. Siswa mengeluh dengan keadaan lapangan yang panas, mengeluh capek, dan akhirnya semangat belajarnya kurang. Hal ini karena model pembelajaran yang digunakan tidak menarik, tidak menumbuhkan motivasi siswa dan tidak membuat siswa menjadi aktif belajar. Pada akhirnya hasil belajar siswa rendah (Mills dkk. 2020; Schiappa dan Smith 2019; Sit dan Brudzinski 2017).

Kondisi rendahnya retensi hasil belajar pada geologi pertambangan tersebut harus segera diatasi agar hasil belajar dapat menjadi dasar tumbuh kembangnya pengetahuan, sikap, dan keterampilan. Salah satu upaya mengatasi kondisi rendahnya retensi hasil belajar adalah dengan menerapkan model pembelajaran yang sesuai selama proses pembelajaran. Pengembangan Model Pembelajaran Saintiifk Berbasis Google Earth melalui beberapa tahap. Tahap pertama yakni analisis kebutuhan. Tahap kedua yakni validasi rancangan model pembelajaran dari hasil analisis kebutuhan. Tahap ketiga ialah hasi implementasi model pembelajaran yang telah divalidasi.

Tahap analisis kebutuhan menghasilkan rancangan model pembelajaran berbasis Google Earth. Model ini dikembangkan untuk meningkatkan hasil belajar siswa. Hasil belajar siswa dapat meningkat dikarenakan model ini menggunakan teknologi geospasial berupa Google Earth yang terintegrasi dengan setiap sintak pembelajaran. Selain itu pembelajaran ini juga memasukkan kegiatan praktikum lapangan (fieldwork) untuk mengasah keterampilan siswa. Dengan kedua upaya tersebut rancangan model ini diyakini mampu meningkatkan retensi hasil belajar siswa.

Tahap analisis kebutuhan juga memperhatikan Kompetensi Dasar (KD) dalam pelajaran pemetaan geologi. KD yang dipilih ialah KD 3.15 Menganalisis struktur geologi (Pengetahuan) dan KD 4.15 Menyajikan hasil analisis struktur geologi (Keterampilan). Dari KD tersebut kemudian disusun tujuan pembelajaran, yaitu; 3.15.1 Menjelaskan jenis-jenis struktur geologi; 3.15.2 Menjelaskan prosedur pengambilan data struktur geologi; 3.15.3 Menentukan struktur geologi di suatu daerah; dan 4.15.1 Melakukan pengambilan data struktur geologi serta 4.15.2 Mempresentasikan hasil analisis struktur geologi (kedalam peta geologi). KD dan tujuan pembelajaran yang telah ditentukan tersebut selanjutnya diaplikasikan ke dalam model pembelajaran berbasis Google Earth.

Tahap kedua merupakan hasil dari uji validasi rancangan. Secara umum rancangan yang dibuat sudah dinyatakan valid $85,23 \%$. Beberapa koreksi dan saran dari validator telah membantu penyempurnaan model pembeajaran berbasis Google Earth ini. Hal ini karena pengalaman validator selama mengajar TIK di SMK, sehingga dari itu diperoleh masukan yang sangat bermanfaat. Tahap ketiga ialah uji implementasi. Dalam tahap ini selama proses pembelajaran peneliti mengamati kejadian-kejadian yang ada pada siswa yang ditimpulkan oleh tiap-tiap sintaks pembelajaran berbasis Google Earth.

Langkah 1. Mengidentifikasi citra Google Earth. Pada langkah ini guru harus sudah menentukan tujuan pembelajaran. Tujuan pembelajaran berupa menjelaskan jenis-jenis struktur geologi (Kompetensi Dasar Pengetahuan) dan mempresentasikan hasil analisis struktur geologi (Kompetensi Dasar Keterampilan). Google Earth dalam sintak 1 ini digunakan sebagai sarana virtual field experiences (VFE) menggunakan virtual globe (Dolphin, Dutchak, Karchewski, \& Cooper, 2019). Hal ini dilakukan karena untuk melakukan fieldwork secara terus menerus sangat sulit dilaksanakan.

Siswa selama melaksanakan langkah pembelajaran 1. diminta untuk melakukan identifikasi struktur-struktur geologi yang ada pada daerah yang akan dipetakan. Dengan bantuan Google Earth, siswa tidak harus datang langsung ke daerah yang dipetakan tersebut. Siswa cukup dengan mengidentifikasi di depan komputer yang telah terinstal Google Earth. Hal ini sesuai 
dengan saran dari Bodzin, Anastasio, \& Kulo (2014), bahwa langkah pertama pembelajaran berupa deesain kurikulum. Dengan melakukan identifikasi pada daerah yang akan dipetakan siswa sudah belajar secara kontekstual. Kontekstual di sini dapat dilakukan dengan mendekatkan materi ajar dengan lingkungan belajar siswa.

Langkah 2. Merumuskan permasalahan yang bersumber dari identifikasi citra Google Earth. Hasil identifikasi jenis-jenis struktur geologi yang siswa temukan pada citra Google Earth kemudian dijadikan dasar dalam merumuskan masalah. Siswa merumuskan masalah dalam bentuk kalimat tanya. Pada langkah ini kekhawatiran para peneliti terhadulu (Gagnier dkk. 2017) dapat diminimalisir, melalui pemanfaatan Google Earth. Langkah 2. membuat rumusan masalah ini merupakan bentuk dari pembelajaran yang menggunakan pendekatan pemecahan masalah (problem solving). Problem solving terbukti menghasilkan kesuksesan belajar geologi (Balliet, Riggs, \& Maltese, 2015). Dengan langkah seperti ini siswa akan belajar geologi untuk mengatasi masalah-masalah yang akan ditemui selama pembelajaran, sehingga akan tertanam pada diri mereka. Ini juga dapat membantu siswa dalam menerjemahkan bentuk 2D ke dalam fenomena geologi (Mathiesen dkk. 2012). Siswa setiap menemukan permasalah, akan merumuskannya terlebih dahulu sebelum menyelesaikan permasalahan.

Langkah 3. Melakukan pemasukan data yang didapat dari lapangan ke dalam Google Earth. Siswa melakukan cek lapangan (fieldwork) untuk memasukkan data berupa pengukuran strike dan dip sebagai kegiatan pengambilan data primer. Siswa dituntut untuk aktif melakukan pengukuran strike dan dip agar keterampilannya meningkat. Data tersebut kemudian dimasukkan ke dalam Google Earth. Dari lngkah ini siswa yang memiliki kemampuan visualisasi yang baik dan tidak hanya menghafal dan menerapkan aturan dan telah membantu belajar struktur geologi sesuai harapan Whitmeyer dkk., (2012). Data primer strike dan dip nantinya dapat digunakan untuk menganalisis Data geologi meliputi; batuan (penyebaran, jenis, dimensi, kedudukan, susunan); struktur geologi: sesar, lipatan, dan kekar); dan proses-proses yg berkembang pada suatu daerah.

Langkah 4. Memanfaatkan fitur-fitur Google Earth untuk mengolah data lapangan agar dapat menjawab rumusan masalah. Siswa dalam tahap ini megolah data yang didapat saat fieldwork (data primer) berupa strike dan dip dengan menggunakan fitur-fitur Google Earth. Hal ini juga dimungkingkan untuk membuat siswa aktif mengeksplorasi fitur Google Earth untuk dapat menampilkan data primer dalam citra pada masing-masing komputer siswa. Langkah 4. ini termasuk dalam mendesain aktivitas untuk menggabungkan dua sifat utama: skalabilitas dan portabilitas (Bodzin dkk. 2014). Dalam mendesain pembelajaran dengan Google Earth, guru harus memperhatikan/mengingat bahwa tampilan pada Google Earth merupakan gambar yang sudah diskalakan, dan keadanyanya sudah portabel (mudah dibawa-bawa). Bersamaan dengan itu, langkah ini sesuai dengan saran Bodzin, Anastasio, \& Kulo (2014) bahwa desain gambar harus merepresentasikan aspek visual yang ilmiah. Gambar-gambar yang akan didesain oleh siswa selama pembelajaran, harus berdasarkan kebenaran secara ilmu geologi. Dengan begitu siswa akan mempelajari sesuatu fenomena geologi secara benar. Langkah 4. Juga mengikuti saran Bodzin, Anastasio, \& Kulo (2014), bahwa pembelajaran harus menggunakan ikon/simbol yang menggambarkan konsep dunia nyata. Simbol yang digunakan dalam pembelajaran berbasis Google Earth harus sesuai dengan simbol yang ada pada ketentuan penggunaan simbol peta geologi dan peta topografi.

Langkah 5. Mempresentasikan hasil jawaban dari rumusan masalah menggunakan Google Earth. Siswa melakukan presentasi menggunakan LCD. Siswa dalam presentasi memberikan jawaban atas rumusan masalah yang mereka buat. Selanjutnya siswa menjelaskan jawaban tersebut sesuai yang ditampilkan di Google Earthnya. Langkah ini mengharapkan siswa untuk dapat melakukan komunikasi secara efektif. Siswa belajar menyampaikan ide atau 
gagasan, dimulai dari melakukan identifikasi pada Langkah 1., kemudian merumuskan masalah, dan pada akhirnya presentasi dilakukan untuk menyampaikan jawaban atas rumusan masalah. Dengan demikian siswa belajar geologi secara saintifik. Hasil belajar siswa dalam ketiga aspek pengetahuan, sikap dan keterampilan setelah menggunakan model pembelajaran berbasis Google Earth meningkat. Hal ini berarti bahwa hasil belajar merupakan buah dari suatu proses aktivitas mental seseorang dalam berinteraksi dengan lingkungannya sehingga menghasilkan perubahan tingkah laku yang bersifat positif baik perubahan dalam aspek pengetahuan, sikap, maupun psikomotor.

Pembelajaran berbasis Google Earth menghasilkan lingkungan belajar yang inovatif. Pembelajaran ini menghadirkan sebuah tampilan teknologi geospasial yang membuat siswa tertarik untuk belajar. Pembelajaran ini didukung kegiatan fieldwork untuk memperoleh data lapangan yang kemudian dari data tersebut kembali diolah dengan Google Earth memberikan tantangan bagi siswa, sehingga siswa terlibat aktif dalam belajar. Aktifnya siswa dalam pembelajaran juga didukung peningkatan motivasi siswa untuk menghasikan peta geologi yang baik.

Hasil belajar yang meningkat dengan penggunaan model pembelajaran berbasis Google Earth ini juga sejalan dengan pendapat Kafai \& Dede (2014). Pembelajaran berbasis Google Earth yang virtual ini dapat mendukung pengalaman belajar yang kompleks, mendukung eksplorasi secara mandiri, sangat menarik dan memotivasi, serta memberikan cara pandang baru dalam melakukan penilaian otentik, otomatis, dan tertanam secara baik.

Pembelajaran berbasis Google Earth efektif digunakan dalam pembelajaran geologi. Efektifitas pembelajaran ini sesuai dengan hasil penelitian Oktavianto (2017). Hal ini dikarenakan; (1) siswa merasa tertantang untuk menyelesaikan tugas yang berhubungan dengan permasalahan yang nyata (fieldwork); (2) keaktifan siswa selama pembelajaran meningkat; (3) siswa lebih teratur dalam mengerjakan tugasnya; (4) siswa lebih leluasa dalam mengerjakan proyek; (5) siswa bersemangat kompetisi dengan siswa lainnya dalam menghasilkan produk terbaik. Efektifitas pembelajaran Google Earth didukung dengan data dan fakta bahwa hasil belajar siswa meningkat setelah penggunaan model pembelajaran ini.

Efektifitas pembelajaran berbasis Google Earth juga sesuai dengan hasil penelitian terhadulu (Awada dan Diab 2018; Dolphin dkk. 2019; Kortz dkk. 2017; Martínez-Graña dkk. 2014). Pembelajaran Google Earth efektif karena dapat diakses secara gratis, dan mudah digunakan, sehingga memudahkan dalam membedakan bentang lahan alamiah dan buatan, membantu belajar memvisualkan, dan memahami proses yang terjadi di permukaan bumi (Oktavianto, 2019). Google Earth yang terbukti mampu membantu siswa dalam meningkatkan keterampilan spasial (Xiang dan Liu 2017), termasuk di dalamnya mengenai keterampilan membaca peta (Oktavianto, 2018), ternyata juga terbukti mampu membantu siswa dalam membuat peta geologi.

Langkah 1. yang berupa identifikasi citra dari Google Earth efektif untuk membangun pengetahuan awal siswa. Siswa dapat membedakan bentang alam alamiah dan buatan. Dengan membedakan dua bentang alam tersebut siswa merasa hadir dalam daerah yang dilihatnya (Dolphin dkk. 2019). Apalagi daerah tersebut tidak terlalu jauh dari sekolah ataupun tempat tinggal siswa (masih dalam lingkup kabupaten yang sama). Langkah 2. berupa merumuskan masalah. Dalam merumuskan masalah yang akan diselesaikan, secara tidak langsung siswa juga dituntut untuk memverifikasi masalah yang ditemui. Setelahnya, siswa juga dibawa untuk berpikir tentang langkah-langkah penyelesaian masalah. Jadi, mulai pada langkah ini siswa sudah mulai berpikir tentang problem solving.

Langkah 3. Pengumpulan data. Pada langkah ini sebelum data dikumpulkan, siswa dibawa ke daerah yang akan dipetakan untuk mendapat data lokasi, strike, dan dip. Data-data 
tersebut merupakan data yang berupa informasi spasial atau bereferensi keruangan. Dengan pembelajaran fieldwork seperti ini siswa dilatih keterampilan seorang geolog. Data kemudian dimasukkan ke dalam Google Earth, sehingga hasilnya dapat ditampilkan pada tampilan yang ada pada Google Earth. Langkah 4. Memanfaatkan fitur-fitur Google Earth. Berbagai fitur yang ada pada Google Earth dapat menampilkan data yang dihasilkan dari fieldwork secara lebih atraktif, data fieldwork yang berupa informasi spasial (bereferensi keruangan) dapat ditampilkan pada Google Earth dengan sangat baik. Siswa dapat memberikan warna sesuai dengan yang mereka inginkan, namun seharusnya pemilihan warna disesuaikan dengan SNI Pemetaan Geologi.

Langkah 5. Mempresentasikan hasil pengolahan data dengan Google Earth. Tahap ini melatih anak untuk dapat berkomunikasi. Dengan bantuan Google Earth, siswa dapat menampilkan presentasi yang interaktif, sehingga merangsang siswa lain untuk memberi saran, tanya jawab, dan kritik bagi siswa yang mempresentasikan. Presentasi ini merupakan bentuk komunikasi. Ini sesuai dengan yang disampaikan Berry (2013) bahwa sistem komunikasi interaktif atau clickers dapat meningkatkan keaktifan siswa.

\section{KESIMPULAN}

Hasil penelitian yang telah dilakukan dapat disimpulkan; (1) Hasil belajar siswa sebelum menggunakan model pembelajaran berbasis Google Earth rendah; (2) Langkah-langkah pembuatan model pembelajaran saintifik berbasis Google Earth menghasilkan sintak (langkah) pembelajaran berbasis Google Earth, sebagai berikut; Langkah 1. Mengidentifikasi citra Google Earth sesuai dengan tujuan pembelajaran; Langkah 2. Merumuskan permasalahan yang bersumber dari identifikasi citra Google Earth; Langkah 3. Melakukan pemasukan data yang didapat dari lapangan ke dalam Google Earth; Langkah 4. Memanfaatkan fitur-fitur Google Earth untuk mengolah data lapangan agar dapat menjawab rumusan masalah; Langkah 5. Mempresentasikan hasil jawaban dari rumusan masalah menggunakan Google Earth; dan (3) Hasil belajar siswa setelah menggunakan model pembelajaran saintifik berbasis Google Earth mengalami peningkatan yang signifikan, sehingga dapat dikatakan model ini efektif digunakan.

Dari kesimpulan yang telah didapat, maka peneliti memberi saran; (1) Guru perlu menggunakan model pembelajaran yang cocok dengan karakteristik materi, agar hasil belajar siswa tidak rendah; (2) Langkah-langkah pembelajaran berbasis Google Earth harus dilaksanakan secara berurutan sesuai dengan pendekatan saintifik; (3) Data yang dimasukkan dalam Google Earth harus berupa data atau informasi spasial (bereferensi keruangan); dan (4) Pembelajaran dengan Google Earth efektif dilakukan untuk materi-materi yang mempunyai data atau memiliki informasi spasial untuk materi-materi yang tidak mempunyai data atau informasi spasial, model pembelajaran ini perlu diuji cobakan lebih lanjut.

\section{UCAPAN TERIMA KASIH}

Penelitian ini didanai oleh Direktorat Kesharlindung Direktorat Jenderal Guru dan Tenaga Kependidikan (GTK) Kementerian Pendidikan dan Kebudayaan Republik Indonesia pada Tahun 2019.

\section{DAFTAR PUSTAKA}

Almquist, Heather, Lisa Blank, dan Jennifer Estrada. 2012. "Developing a Scope and Sequence for Using Google Earth in the Middle School Earth Science Classroom." dalam Google 
Earth and Virtual Visualizations in Geoscience Education and Research. Geological Society of America.

Awada, Ghada, dan Hassan B. Diab. 2018. "The Effect of Google Earth and Wiki Models on Oral Presentation Skills of University EFL Learners." International Journal of Teaching and Learning in Higher Education 30(1):36-46.

Balliet, Russell N., Eric M. Riggs, dan Adam V. Maltese. 2015. "Students' Problem Solving Approaches for Developing Geologic Models in the Field." Journal of Research in Science Teaching 52(8):1109-31. doi: 10.1002/tea.21236.

Bodzin, Alec M., David Anastasio, dan Violet Kulo. 2014. "Designing Google Earth Activities for Learning Earth and Environmental Science." Hlm. 213-32 dalam Teaching Science and Investigating Environmental Issues with Geospatial Technology: Designing Effective Professional Development for Teachers, disunting oleh J. MaKinster, N. Trautmann, dan M. Barnett. Dordrecht: Springer Netherlands.

De Donatis, Mauro, Sara Susini, dan Marco Foi. 2012. "Geology from Real Field to 3D Modeling and Google Earth Virtual Environments: Methods and Goals from the Apennines (Furlo Gorge, Italy)." dalam Google Earth and Virtual Visualizations in Geoscience Education and Research. Geological Society of America.

Dolphin, Glenn, Alex Dutchak, Brandon Karchewski, dan Jon Cooper. 2019. "Virtual field experiences in introductory geology: Addressing a capacity problem, but finding a pedagogical one." Journal of Geoscience Education 67(2):114-30. doi: 10.1080/10899995.2018.1547034.

Farmer, E. Christa, Amy J. Catalano, dan Adam J. Halpern. 2020. "Exploring Student Preference between Textbook Chapters and Adaptive Learning Lessons in an Introductory Environmental Geology Course." TechTrends 64(1):150-57. doi: 10.1007/s11528-01900435-w.

Gagnier, Kristin M., Kinnari Atit, Carol J. Ormand, dan Thomas F. Shipley. 2017. "Comprehending 3D Diagrams: Sketching to Support Spatial Reasoning." Topics in Cognitive Science 9(4):883-901. doi: https://doi.org/10.1111/tops.12233.

Kafai, Yasmin B., dan Chris Dede. 2014. "Learning in Virtual Worlds." Hlm. 522-42 dalam The Cambridge Handbook of the Learning Sciences, Cambridge Handbooks in Psychology, disunting oleh R. K. Sawyer. Cambridge: Cambridge University Press.

Kortz, Karen M., Andrea M. Grenga, dan Jessica J. Smay. 2017. "Establishing and Applying Literature-Based Criteria for Effective Communication of Science to Novices Via Introductory Geology Textbooks." Journal of Geoscience Education 65(1):48-59. doi: 10.5408/16-205.1.

Lamb, Annette, dan Larry Johnson. 2010. "Virtual Expeditions: Google Earth, GIS, and Geovisualization Technologies in Teaching and Learning."

Lamotte, Dominique Frizon de, Pascale Leturmy, Pauline Souloumiac, Adrien Frizon de Lamotte, Pascale Leturmy, Pauline Souloumiac, dan Adrien Frizon de Lamotte. 2020. Geological Objects and Structures in 3D: Observation, Interpretation and Building of 3D Models. CRC Press.

Martínez-Graña, Antonio Miguel, José González-Delgado, Silvia Pallarés, José Luis Goy, dan Jorge Civis Llovera. 2014. "3D Virtual Itinerary for Education Using Google Earth as a Tool for the Recovery of the Geological Heritage of Natural Areas: Application in the 'Las Batuecas Valley' Nature Park (Salamanca, Spain).” Sustainability 6(12):1-25.

Mathiesen, D., T. Myers, I. Atkinson, dan J. Trevathan. 2012. "Geological Visualisation with Augmented Reality." Hlm. 172-79 dalam 2012 15th International Conference on Network-Based Information Systems. 
Mills, Reece, Louisa Tomas, Chrystal Whiteford, dan Brian Lewthwaite. 2020. "Developing Middle School Students' Interest in Learning Science and Geology Through Slowmation." Research in Science Education 50(4):1501-20. doi: 10.1007/s11165-0189741-8.

Nikolopoulou, Kleopatra. 2018. "Creativity and ICT: Theoretical Approaches and Perspectives in School Education." Hlm. 87-100 dalam Research on e-Learning and ICT in Education: Technological, Pedagogical and Instructional Perspectives, disunting oleh T. A. Mikropoulos. Cham: Springer International Publishing.

Oktavianto, Dwi Angga. 2017. "Pengaruh Pembelajaran Berbasis Proyek Berbantuan Google Earth Terhadap Keterampilan Berpikir Spasial.” Jurnal Teknodik 21(1):059. doi: 10.32550/teknodik.v21i1.227.

Oktavianto, Dwi Angga. 2018. "Pengembangan Spatial Thinking On Map Test (Stmt) Untuk Tingkat SMA." Jurnal Teknodik 21(3):73. doi: 10.32550/teknodik.v21i3.345.

Oktavianto, Dwi Angga. 2020. "Model Pembelajaran Investigasi Kelompok Untuk Menganalisis Bentang Alam Hasil Gaya Geologi Melalui Penggunaan Google Earth.” Jurnal Teknodik 0(0):1-14. doi: 10.32550/teknodik.v0i0.512.

Paor, Declan G. De, Mladen M. Dordevic, Paul Karabinos, Stephen Burgin, Filis Coba, dan Steven J. Whitmeyer. 2017. "Exploring the reasons for the seasons using Google Earth, 3D models, and plots." International Journal of Digital Earth 10(6):582-603. doi: 10.1080/17538947.2016.1239770.

Schiappa, Tamra A., dan Langdon Smith. 2019. "Field experiences in geosciences: A case study from a multidisciplinary geology and geography course." Journal of Geoscience Education 67(2):100-113. doi: 10.1080/10899995.2018.1527618.

Sit, Stefany M., dan Michael R. Brudzinski. 2017. "Creation and Assessment of an Active ELearning Introductory Geology Course.” Journal of Science Education and Technology 26(6):629-45. doi: 10.1007/s10956-017-9703-3.

Trofimov, V. T., dan V. A. Korolev. 2019. "Logical and Graphic Models of the Structure and Contents of the General Theory of Engineering Geology and Its Disciplines." Moscow University Geology Bulletin 74(5):496-503. doi: 10.3103/S0145875219050132.

Whitmeyer, Steven J., John E. Bailey, Declan G. De Paor, dan Tina Ornduff. 2012. Google Earth and Virtual Visualizations in Geoscience Education and Research. Geological Society of America.

Xiang, X., dan Y. Liu. 2017. "Understanding 'Change' through Spatial Thinking Using Google Earth in Secondary Geography." Journal of Computer Assisted Learning 33(1):65-78. doi: https://doi.org/10.1111/jcal.12166. 